\title{
Multi-year pair-bonding in Murray cod (Maccullochella peelii)
}

\author{
Alan J Couch ${ }^{\text {Corresp., }}{ }^{1}$, Fiona Dyer ${ }^{1}$, Mark Lintermans ${ }^{1}$ \\ ${ }^{1}$ Centre for Applied Water Science, University of Canberra, Canberra, ACT, Australia \\ Corresponding Author: Alan J Couch \\ Email address: alan.couch@canberra.edu.au
}

Mating strategies in fishes are known to include polygyny, polyandry and monogamy and provide valuable insights regarding powerful evolutionary forces such as sexual selection. Monogamy is a complex of mating systems that has been relatively neglected. Previous work on mating strategies in fishes has often been based on observation and focused on marine species rather than freshwater fishes. SNPs are increasingly being used as a molecular ecology tool in non-model organisms, and methods of probabilistic genetic analysis of such datasets are becoming available for use in the absence of parental genotypes. This approach can be used to infer mating strategies. The long-term pair bonding seen in mammals, reptiles and birds has not been recorded in freshwater fishes in every other respect an extremely diverse group. This study shows that multi-year pair bonding occurs in an Australian Percichthyid fish that exhibits paternal care of eggs and larvae. Using SNPs, full sibling pairs of larvae were found over multiple years in a threeyear study. Stable isotope signatures of the larvae support the genetic inference that full sibling pairs shared a common mother, the ultimate source of that isotopic signature during oogenesis. Spatial and temporal clustering also suggests that the full sibling larvae are unlikely to be false positive identifications of the probabilistic identification of siblings. For the first time, we show multi-year pair bonding in a wild freshwater fish. This will have important conservation and management implications for the species. This approach could provide insights into many behavioural, ecological and evolutionary questions, particularly if this is not a unique case. Our findings are likely to initiate interest in seeking more examples of monogamy and alternative mating strategies in freshwater fishes, particularly if others improve methods of analysis of SNP data for identification of siblings in the absence of parental genotypes. 
Multi-year pair-bonding in Murray cod (Maccullochella peelii)

Alan Couch ${ }^{1}$, Fiona Dyer ${ }^{2}$, Mark Lintermans ${ }^{3}$,

${ }^{1}$ Centre for Applied Water Science, University of Canberra, Bruce, ACT, Australia

${ }^{2}$ Centre for Applied Water Science, University of Canberra, Bruce, ACT, Australia

${ }^{3}$ Centre for Applied Water Science, University of Canberra, Bruce, ACT, Australia

Corresponding Author:

Alan Couch ${ }^{1}$

Centre for Applied Water Science, University of Canberra, Kirinari Street, Bruce, ACT, 2617, Australia

Email address: Alan.Couch@canberra.edu.au 


\section{Multi-year pair-bonding in Murray cod (Maccullochella peelii)}

\subsection{Abstract}

3 Mating strategies in fishes are known to include polygyny, polyandry and monogamy and provide

4 valuable insights regarding powerful evolutionary forces such as sexual selection. Monogamy is a

5 complex of mating systems that has been relatively neglected. Previous work on mating strategies

6 in fishes has often been based on observation and focused on marine species rather than freshwater

7 fishes. SNPs are increasingly being used as a molecular ecology tool in non-model organisms, and

8 methods of probabilistic genetic analysis of such datasets are becoming available for use in the

9 absence of parental genotypes. This approach can be used to infer mating strategies. The long-term pair bonding seen in mammals, reptiles and birds has not been recorded in freshwater fishes - in every other respect an extremely diverse group. This study shows that multi-year pair bonding occurs in an Australian Percichthyid fish that exhibits paternal care of eggs and larvae. Using SNPs, full sibling pairs of larvae were found over multiple years in a three-year study. Stable isotope signatures of the larvae support the genetic inference that full sibling pairs shared a common mother, the ultimate source of that isotopic signature during oogenesis. Spatial and temporal clustering also suggests that the full sibling larvae are unlikely to be false positive identifications of the probabilistic identification of siblings. For the first time, we show multi-year pair bonding in a wild freshwater fish. This will have important conservation and management implications for the species. This approach could provide insights into many behavioural, ecological and evolutionary questions, particularly if this is not a unique case. Our findings are likely to initiate interest in seeking more examples of monogamy and alternative mating strategies in freshwater fishes, particularly if others improve methods of analysis of SNP data for identification of siblings in the absence of parental genotypes.

\subsection{Introduction}

Pair-bonding is widely documented among vertebrates and is reported in mammals, birds, reptiles, and fish. Pair-bonding is often associated with monogamy, site fidelity, shared parental care and a strong affinity between individuals (de Waal \& Gavrilets, 2013), but none of these characteristics is exclusive to pair-bonded animals. Pair-bonding may be short, medium, long-term or even lifelong. Monogamy is a complex of mating systems that has been relatively neglected (Mock \& 
30 Fujioka, 1990). Fish are under-represented in the pair-bonding literature generally, but there is little

31 reason to suppose it does not occur as a successful mating strategy in the fishes with their diverse

32 and ancient evolutionary lineages. There are examples of pair-bonding in marine species such as

33 the seahorse (Hippocampus whitei Bleeker, 1855) (Vincent \& Sadler, 1995; Hippocampus

34 subelongatus Castelnau, 1873)(Kvarnemo et al., 2000) the French angelfish (Pomacanthus paru

35 Bloch, 1787) (Whiteman \& Côte, 2004), hawkfish (Donaldson, 1989)and the Ceratiidae family of

36 Lophiiformes (Anglerfish) (Turner, 1986). Although genetic monogamy is thought to be

37 uncommon in fish (Tatarenkov et al., 2006) it has been seen in bonnethead sharks (Sphyrna tiburo

38 Linnaeus, 1758) (Chapman et al., 2004) and cichlids (Steinwender, Koblmüller \& Sefc, 2012;

39 Takahashi \& Ochi, 2012).

40 Evidence of other mating strategies in fish is common. Polyandry is reported in sandbar

41 (Carcharhinus plumbeus Nardo, 1827), bignose (Carcharhinus altimus Springer, 1950) and

42 Galapagos sharks (Carcharhinus galapagensis Snodgrass and Heller, 1905) (Daly-Engel et al.,

43 2006) and Teleosts such as the lingcod (Ophiodon elongatus Girard, 1854) (King \& Withler,

44 2005). Harem polygyny is known in an obligate coral-dwelling fish, the pygmy coral croucher

45 (Caracanthus unipinna Gray, 1831) (Wong, Munday \& Jones, 2005). Channel catfish (Ictalurus

46 punctatus Rafinesque, 1818) provide a rare suspected example of genetic monogamy in a fish

47 species with uniparental offspring care (Tatarenkov et al., 2006).

There are six hypotheses suggested for the evolution of monogamous pair-bonds (Whiteman \& Côte, 2004). These authors show that paternal care may act to increase the likelihood of monogamy in combination with each of the proposed hypotheses through decreased benefits to males from searching for additional mates or increased advantages to females from sequestering a single high-quality mate (Whiteman \& Côte, 2004). Other researchers also argue that monogamy results from the need to guarantee a high-quality mate and territory in a competitive environment (Morley \& Balshine, 2002).

Fish species have highly diverse breeding behaviors that make them valuable for testing theories on genetic mating systems and reproductive tactics (Avise et al., 2002) but medium, long or lifelong pair-bonding in freshwater species in the wild has not been reported in the literature. One example of short-term pair-bond has been demonstrated experimentally in a mouthbrooding 
60 cichlid (Xenotilapia rotundiventralis Takahashi, Yanagisawa \& Nakaya, 1997). This is

61 demonstrable because of its genetic monogamy and parental care requiring the transfer of embryos

62 from the female to the male after three days (Takahashi \& Ochi, 2012). Similarly DeWoody et al.,

632000 showed monogamy in largemouth bass (Micropterus salmoides Lacepède, 1802). Another

64 example of monogamy is seen in Neolamprologus pulcher Trewavas \& Poll, 1952 (Desjardins et

65

66

67

68

69

70

71

72

al., 2008). These genetically identified monogamous pairings each were for a single breeding event. There is no obvious intrinsic reason for long-term pair-bonding to be underrepresented in the repertoire of freshwater fishes mating systems.

The absence of identification of long-term pair-bonding in freshwater species may have a number of explanations. For example, there may have been less research effort compared with marine systems, perhaps because making observational studies in turbid or high-energy freshwater systems is very difficult. Tagging or radio-tracking adult fish in freshwater systems could produce circumstantial evidence of pair-bonding, but even this sort of long-term or periodic co-location evidence has not been reported. Modern genetic techniques, particularly genome reduction methods with a large number of markers available, and the development of bioinformatics methods to analyse these larger data sets, along with the relevant spatial and temporal data, now allows for cost-effective identification of genetic monogamy and pair-bonding (Macdonald et al. (2005), Razick 2016, Bayerl et al., 2018).

\subsubsection{Identifying Pair-Bonds in an Australian Freshwater Fish}

The iconic Australian Murray cod (Maccullochella peelii) (Mitchell, 1938) is one of four morphologically cryptic but genetically distinct species within Maccullochella (Rowland, 1993; Nock et al., 2010). The Murray cod is Australia's largest freshwater fish and can grow to as large as $180 \mathrm{~cm}$ in length with a maximum recorded weight of $113.6 \mathrm{~kg}$. Its fecundity ranges from 9,000-120,000 eggs annually. The species is highly sought after by anglers. It is limited to parts of the Murray-Darling Basin (MDB) and is listed as vulnerable under the Australian Environment Protection and Biodiversity Conservation Act (1999) (Department of Environment, 2016). Murray cod still form an important recreational fishery (Lintermans \& Phillips, 2005; Koehn \& Todd, 2012; Ye et al., 2016).

Murray cod is a species worth studying for potential evidence of long-term pair-bonding and alternative mating strategies. Male Murray cod are known to provide parental care to both eggs and 
90 larvae for up to 20 days after preparing a nest area. They are long-lived (up to 48 years), slow91 maturing (Lintermans, 2007) and show high site fidelity (Koehn \& Nicol, 2016). These are life

92 history factors associated with long-term pair-bonding in other species Kleiman, 1981; Barlow, 93 1988; Arnold and Owens, 1998; Hatchwell and Komdeur, 2000; Chapple, 2003. Murray cod have 94 been shown to exhibit monogamous mating, as well as polygyny and polyandry over three 95 breeding seasons when held captive in ponds (Rourke et al., 2009).

96 In this study single nucleotide polymorphisms (SNPS) were used to look for sibling relationships 97 of Murray cod larvae and these data, in combination with relevant metadata, were used to infer the 98 existence of multi-year pair-bonding as a mating strategy. The probability of multi-year pair-

99 bonding occurring is considered. Although SNPS are increasingly being used to identify parentage

100 (Vandeputte and Haffray, 2004; Huisman, 2017) confidence in the methods is still developing. For 101 this reason stable isotope evidence is provided to support the genetic findings. This reduces the 102 possibility that any relatedness found was not due to contamination during sample processing, or is 103 merely an artefact of the probabilistic approach to inferring sibship relationships in the absence of 104 known parentals.

\subsection{Methods}

106 This study combines spatial and temporal data from three years of larval sampling with genomic

107 data (SNPS) to infer relationships between larval Murray cod. Carbon and Nitrogen stable isotope

108 data is used to validate the relationship data that has been generated.

\section{1.3.1 Study Site}

110 We sampled Murray cod larvae from six sites along a 50km upland reach of the in Murrumbidgee

111 River in the Australian Capital Territory (ACT), Australia (Figure 1).

\section{1.3.2 Larval Fish Collection, Identification, Preparation and Aging}

113 Data were collected as previously described in Couch et al. (2016). Specifically we examined 261

114 of 2607 Maccullochella larvae which were collected in 2011, 2012, and 2013 from the six sites

115 (Figure 1) using larval driftnets. The sympatric Maccullochella species Trout cod (M.

116 macquariensis) and hybrid larvae were identified using a combination of SNPs and mitochondrial

117 DNA sequencing (Couch et al. 2016). These were excluded from the dataset leaving 251 larval

118 Murray cod used for this analysis. Larvae and tissue samples were preserved in 95\% ethanol at 
119 room temperature until 2014 after which samples were stored at $-20^{\circ} \mathrm{C}$. Fish were collected under

120 ACT Government licences LT2011516, LT2012590 and LT20133653. The research was

121 conducted under approvals CEAE 11-15 and CEAE 13-17 from the University of Canberra

122 Committee for Ethics in Animal Experimentation.

123 1.3.2.1 Age of Larval Fish

124 Age estimation has previously been based on larval length (Koehn \& Harrington, 2006), larval 125 otolith diameter (Vogel, 2003) and daily growth increments in larval Murray cod

126 otoliths (Humphries, 2005). In the present study, age was estimated using a combination of the

127 above methods. Estimates were made based on otolith size using the mean sagittal otolith length of

128 both otoliths where possible for each larva. While this is less accurate than daily increment ageing

129 it does allow many more larvae to be aged in the time available. Mean otolith lengths of both

130 sagittal otoliths were calculated for 365 larvae. Subsets of 29 of 84, 29 of 51 and 31 of 230 were

131 aged by a commercial provider for the years 2011, 2012, 2013 respectively. From this, a curve was

132 developed for each year and estimated ages, based on mean otolith length, was calculated (Couch, 133 2018).

134 1.3.2.2 Estimation of Spawning and Hatch Times

135 Murray cod larva hatch from eggs deposited on hard substrates after 4.5-13 days (depending on 136 water temperature), (Koehn \& O’Connor, 1990; Koehn \& Harrington, 2005, 2006) or 3-8 days 137 (Humphries, 2005), and drift in the water column for some time (Humphries, 2005). In this study, 138 the spawning to hatching time (Incubation) which is known to be a temperature dependent process 139 was estimated using the formula developed by Ryan et al., (2003). That is:

$$
\text { Incubation }_{\text {(duration) }}=20.67-0.667 *\left[\text { WaterTemp }\left({ }^{\circ} \mathrm{C}\right)\right]
$$

Equation 1

140

141 The median of the estimates of the duration of brood care (4-10 days) (Humphries, 2005) and 142 dispersal (4 days) (Gilligan \& Schiller, 2003) were, with larval age, used to back-calculate 143 spawning and hatch dates, as day-of-year (DoY), and from that, dispersal duration. The process, 144 following spawning migration and courtship, can be summarised as: 
Therefore:

148

$$
\operatorname{DoY}_{(\text {Hatch })}=\operatorname{DoY}_{(\text {Capture })}-\text { Age }
$$

Equation 2

149

$$
\operatorname{DoY}_{(\text {Spawning) }}=\operatorname{DoY}_{(\text {Hatch) }}-\text { Duration }_{(\text {Incubation })}
$$

150

$$
\text { Dispersal }_{(\text {duration) }}=\text { Age }- \text { Broodcare }
$$

Equation 4

151

152 Once dispersal, age and capture parameters were known, these equations were then used to

153 calculate hatch and spawning dates.

\section{1.3.3 Putative Nest Location}

155 Individual nest sites are unknown so an estimate of the putative nest site was made based on a

156 mean larval dispersal velocity of 700 metres per day for the duration of the time available for

157 dispersal based on the larva age (Couch, 2018).

\section{1.3.4 Genomic DNA Extraction and Sequencing}

159 Genomic DNA Extraction and Sequencing was performed as previously described in Couch et al.,

160 (2016). Total DNA was isolated from whole larval heads. The DNA extraction protocol is detailed

161 in (Couch \& Young, 2016) and is based on a turtle DNA extraction protocol (FitzSimmons, Moritz

$162 \&$ Moore, 1995). Sequencing was done using Diversity Arrays Technology's (DArT) DArTseq ${ }^{\mathrm{TM}}$

163 which represents a combination of DArT complexity reduction methods and next-generation

164 sequencing platforms (Kilian et al., 2012; Courtois et al., 2013; Cruz, Kilian \& Dierig, 2013;

165 Raman et al., 2014). Sequences generated were processed using proprietary DArT analytical

166 pipelines (www.diversityarrays.com).

\section{1.3.5 Marker Scoring and Statistical Analysis}

168 Marker Scoring and Statistical Analysis was performed as previously described in Couch et al.,

169 (2016). Specifically, DArTsoft (Diversity Arrays Technology, Building 3, University of Canberra,

170 Australia), a software package developed by DArT PL

171 (http://www.diversityarrays.com/software.html), was used to both identify and score the markers

172 that were polymorphic. 
173

174

175

176

177

178

179

180

181

182

183

184

185

186

187

188

189

190

191

192

193

194

195

196

197

198

199

200

201

\subsubsection{SNP Analyses}

SNP Analyses have been described in Couch et al. (2016). Variation in the genome-wide SNP data of the studied Maccullochella genotypes was analysed using Discriminant Analysis of Principal Components (DAPC) using sequential K-means and model selection to infer genetic clusters (Jombart, Devillard \& Balloux, 2010) using R package 'adegenet'version 2.0.1 (Jombart, 2008).

The data were converted into a genlight object (the format required by the software) and three principal components were retained. Two principal components were plotted using ggplot 2 version 2.1 (Wickham, 2009). Summary and comparative statistics were created in R version 3.3.0 (R Development Core Team \& R Core Team, 2013) and Tableau version 9.2 (Tableau, 2013). Maps were created using ArcGIS version 10 (ESRI, 2013) and Tableau.

\subsubsection{Carbon and Nitrogen Stable Isotope Analysis}

Dried muscle material from each fish larva $(0.86 \mathrm{mg} \pm 0.17 \mathrm{SD})$, the bulk of the posterior portion of its body without head and gut of the fish, were encapsulated in tin. Samples were combusted in an elemental analyser mass spectrometer (Sercon, Crewe, United Kingdom) at the Australian National University Research School of Earth Sciences Radiocarbon Laboratory, on a fee-for-service basis and assayed for $\delta^{15} \mathrm{~N}$ and $\delta^{13} \mathrm{C}$ stable isotope ratios and $\mathrm{C}: \mathrm{N}$ ratio. Isotopic signatures were determined based on Australian National University isotopic standards (USGU41, USGU40, Caffeine and Gelatine). Measurement precision was approximately $0.08 \%$ for $13 \mathrm{C}$ and $0.15 \%$ for $15 \mathrm{~N}$. Isotope values are expressed as the relative parts per thousand (\%o).

\subsubsection{Inferring existence of family groups using spatio-temporal data}

Plots were made using hatch date and putative nest location for larvae from each annual cohort. Individual clusters, corresponding to putative nests, were identified and nominated.

\subsubsection{Inferring Sibship using Related}

The probability of relatedness (r) was calculated for individual larval dyads based on the trioml algorithm using 'related' (Pew et al. 2015).

A simulation was run to identify a probability density function for full siblings, parent-offspring, half-siblings, and unrelated individuals using the allele frequencies from the DARTseqs for each larva. A probability estimate that would best estimate the cut-off probability between full siblings and half-siblings was identified and used to subset likely full-sibling dyads from the larval dyads. 
202 Full siblings were assigned a name representing their putative 'mother'. This was arbitrary and

203 could have been assigned a name representing putative 'father'.

204 The relationships between individuals based on the dyads and the probabilities was visualised by 205 making network graphs and plotting them using Gephi (Bastian, Heymann \& Jacomy, 2009) and

206 'r' package 'iGraph'(Csardi \& Nepusz, 2006). The set of dyads containing full siblings was used to

207 prepare network graphs to facilitate visualisation of the family groups and the assignation of a 208 name to putative female parent.

209 1.3.9 Inbreeding Coefficient

210 The two likelihood algorithms - dyadML and trioml - as well as the lynchrd, and ritland algorithms

211 within the 'r' package 'related' can account for inbreeding in their estimates of relatedness. The

212 command "allow.inbreeding=TRUE" was set to output an inbreeding coefficient for each

213 individual under each of the three algorithms above.

214 1.3.10 Comparison of inferred family groups and sibships

215 The plot illustrating family groups previously identified and named using spatio-temporal data

216 alone was then coloured by the name of the putative mother. This comparison increased precision

217 in identification of 'family' groups.

$218 \quad 1.4$ Results

219 1.4.1 Accounting for Outbred Population

220 Using the measures of relatedness ( $\mathrm{r}$ ) calculated using the trioml algorithm it became apparent that

221 there were two distinct groups within the larvae sampled; those that were highly outbred $(\mathrm{r}<-0.4)$,

222 and the rest which were not strongly inbred or outbred $(r>-0.4$ and $<0.3)$. Relatedness amongst the

223 non-outbred fish was used to determine common parentals. Principal component analysis of those

224 larvae considered to be outbred suggested a difference between the two populations. These

225 differences were not correlated with location or year. Fish with a coefficient of inbreeding below -

2260.4 were considered outbreds and separate from the 'river' fish (Figure in supplementary material).

227 These fish were excluded from subsequent related analysis as they were considered likely to be

228 Murray cod introduced from a recent re-stocking program. 
229 1.4.2 Inferring existence of family groups using spatio-temporal data alone.

230 Initially, the existence of family groups was inferred from a scatterplot of spatial and temporal

231 separation of larvae. Figure 2 shows clusters of larvae distributed over space and time.

\section{1.4.3 Nomination of Putative Female Parent}

233 The set of dyads containing full siblings was used to prepare network graphs to facilitate

234 visualisation of the family groups and the assignation of a name to putative female parent. Four

235 female Murray cod mated with the same male for more than one year of the three years sampled

236 (Figure 3). One pair mated for three years sequentially and three other pairs mated for two of the

237 three years studied, one pair detected mating sequentially and two pairs detected mating in non-

238 sequential years.

\section{1.4.4 Comparison of inferred family groups and sibships}

240 A spatio-temporal plot was coloured by the putative female parent of the larvae (Figure 4) and it is

241 a clear correlation between identification of groups by spatio-temporal factors alone and those

242 identified by genetic relatedness of the nest groups.

243 When the Carbon and Nitrogen Isotope ratios of the larvae are considered the strong clustering of

$244 \mathrm{CN}$ isotope ratios and female parent illustrates a high correlation between full sibling status and

245 body isotope signature provided to the larva from its female parent (Figure 5). This also supports

246 the validity of parentage assignment based on related analysis.

247 The identification of sibling relationship is also supported by the limited number of observations

248 (just 3 individuals of 35 full sibling pairs) that were found at separate sites, and those three were

249 only at detected at sites immediately adjacent to the other sibling. These larvae sibling pairs are

250140,$179 ; 133,105$ and 170,191 can be seen in Figure 4.

\subsubsection{Inferring Sibship using Related}

252 Simulation using the allele frequencies present in the population produced the probability density

253 function in figure 6. In this way, the overlap between relatedness values can be assessed. In this

254 case, a 'cutoff' value of any $r$ value above 0.4 was selected to identify most full sibling dyads while

255 minimising the possibility of inadvertently misclassifying half-siblings as full siblings (Figure 6).

256 The possibility of parent-offspring relationships is obviated because all larvae in the analysis were 
257 collected within three years and the sexual maturity of Murray cod is greater than 4-5 years

258 (Lintermans 2007).

259 After identifying the optimal value of $r$ to eliminate dyads least likely to represent full siblings, the

260 set of dyads were filtered to include full siblings only. This resulted in 35 dyads (pairs of full

261 siblings) that were assigned to a family group.

\section{1.4.6 Probability of Observed Multi-Year Pair-Bonding}

263 The multi-year bonding identified in this case is unlikely to be due to chance alone. The probability

264 of multi-year pair-bonding occurring within the cohorts by chance can be estimated if:

and we assume 50/50 sex ratio in accordance with the findings of previous research on the species (Cadwallader, 1977; Koehn \& O'Connor, 1990) then the probability of pairing is:

$$
p=(1 / n-1)^{y}-1
$$

Equation 5

269

270

271

272

273

274

275

276

277

278

279

280

281

282

Applying Equation 5 for an individual female, the probability of mating with the same male for two years is $<0.008$ and for each individual female the probability of mating with the same male for three years is $<0.00005$. Clearly, the probability of four individuals each choosing the same mate for multiple years reduces this probability even further.

To put it another way; for $p$ to even approach non-significance at the 0.05 level, the number of available males would need to be as low as five. Thus it seems unlikely to be random mate selection.

\subsection{Discussion}

This study has, for the first time in the wild, allowed us to infer that some male and female Murray cod pair-bond for more than one year at a time. This suggests that Murray cod exhibit long-term pair-bonding under some conditions. Our study does not provide any evidence that polyandry or polygyny are absent, nor does it provide evidence for or against the coexistence of alternative mating strategies. Data similarly derived on half-siblings status may be able to provide significantly more detail of mating strategies in use. Nevertheless, if pair bonding is a feature of 
283 long-lived freshwater fish, then it has profound implications for management and conservation 284 strategies.

285 Because of the limited numbers of full sibling pairs detected across years (4/35 pairs in three 286 years), it might be concluded from these data that multi-year pair-bonding is not a commonly 287 adopted mating strategy, and this may be the case. However, such a conclusion is considered 288 unwarranted because the spatial and temporal distribution of sampling of the current study reduces the possibility of detecting full siblings by its limited resolution. Furthermore, recreational fishing pressure may reduce the likelihood of identifying multi-year pair-bonds by eliminating some adult fish from the breeding pool each year. Murray cod are an iconic Australian recreational target and are, if stocking numbers are a guide, the second most sought-after native freshwater fish in the Murray-Darling Basin (Reynoldson, 2017) and while recreational fishing regulations prohibit the take of Murray cod during the spawning season (NSW Department of Primary Industries, 2017) catch and release is not prohibited, with the aggressive behaviour of adults during this time well known. The risk of being removed from the seasons breeding cohort even applies to angled fish which are subsequently released, (Henry \& Lyle, 2003) because such fish have been shown to reabsorb oocytes after the stress of capture and release (Cooke \& Suski, 2005). In this case, a female may return to her home territory rather than pursue a breeding opportunity. In turn, the male would then be more likely to select another mate for that breeding season. A similar disruption is also likely should it be the male that is caught and pulled from his nest territory before spawning or while nest guarding. Examining more larvae for sibling pairs would help quantify the prevalence multi-year pair-bonding as a mating strategy. So too would conducting a multi-year study in waters closed to fishing.

305 The probability estimates in this study make some assumptions that need consideration. Firstly, the possibility of all males and females being able to access each other across the study reach was assumed. Movement studies of adult fish elsewhere indicate Murray cod can and sometimes do undertake long spawning migrations (Lintermans, 2007; Koehn \& Nicol, 2016) and there are fewer than five physical barriers to adult fish movement in this reach when river height peaks and some barriers drown-out most years (F. Dyer, M. Lintermans \& A. Couch (2014, unpublished data).

311 While some philopatry is possible in wet years, considerable variation between Murray cod

312 spawning movements has been reported who hypothesised that some individuals may switch

313 between migratory and sedentary behaviours between years (Koehn et al. 2009). What is clear is 
314 that further multi-year fine-scale investigations are required on spawning site use. Secondly, we

315 have assumed that strong size-assortative mating preferences have not unduly limited potential

316 mating partners for individual Murray cod. There is no data on size-assortative mating in Murray

317 cod, but it is potentially a factor that may cause two individual fish to come together

318 disproportionately often. This could be because of size selection per se or because larger fish claim

319 the best nesting sites each year. The authors consider very strong philopatric or assortative mating

320 unlikely and in any case the result is still multi-year pair-bonding.

321 Other physiological and behavioural factors have been associated with monogamy and/or long322 term pair-bonding. Some of these may provide avenues for further understanding details of pair-

323 bonding in Murray cod. These include mate recognition (Sogabe, 2011), hormones such as

324 oxytocin's role in social bonding (Acher, Chauvet \& Chauvet, 1995; Donaldson \& Young, 2008),

325 variation in operational sex ratio (Sogabe \& Yanagisawa, 2007), sexual dimorphism (de Waal \&

326 Gavrilets, 2013), and sex role reversal (Sogabe \& Yanagisawa, 2007).

327 Multi-year bonding in freshwater fish is a novel and important finding that may change attitudes to

328 these animals and angling. It has been seen in captive Murray cod (Rourke et al., 2009) and now

329 evidence of it existing in the wild has implications for decisions of fisheries managers. Efforts to

330 minimise disruption to pair-bond formation may need to reconsider fishing access during the

331 breeding season. This may entail closures rather than prohibition on take which permits catch-and-

332 release. Higher resolution spatial and temporal sampling would allow not only more certainty

333 regarding identified mating strategies employed by the species but also provide valuable data

334 regarding larval dispersal, which still is an important question in Australian freshwater fishes in

335 general and Murray cod in particular.

336 This study was designed primarily to explore spatial and temporal patterns in larval dispersal in an

337 upland river, and any hybridisation with a recently reintroduced formerly sympatric species. That

338 such an exciting finding as hitherto unknown multi-year pair-bonding was detected in part due to

339 serendipity emphasises the knowledge gaps regarding even some basic life history traits of

340 freshwater fish. These include:

341 - When are pair-bonds formed? Early on in courtship, or just before spawning,

342 - Does pair-bonding also occur in reaches where there are no barriers to movement?

343 - Do bonded pairs co-locate during the non-breeding season? 
344 - What are the impacts of catch and release on long-term pair-bonding? Is it seasonal disruption or more permanent?

\section{1.6 Conclusion}

347 Our claim that wild long-term pair-bonding has for the first time been identified within a large

348 group of animals (the freshwater fish of Australia, and perhaps the world) requires more

349 investigation. This study provides a body of evidence - by no means definitive - that such a mating

350 strategy does exist, in at least one freshwater species. This work does not get to the important

351 question of why such a mating strategy may have been adopted by this species. It is however the

352 necessary first step towards such work that may consider this question. Clearly, subsequent work

353 should investigate pair-bonding in Murray cod, and seek to identify pair-bonding in other

354 freshwater fishes in Australia and elsewhere.

\section{$355 \quad 1.7$ References}

356

357

358

359

360

361

362

363

364

365

366

367

368

369

370

371

372

Acher R., Chauvet J., Chauvet MT. 1995. Man and the chimaera. Selective versus neutral oxytocin evolution. Advances in Experimental Medicine and Biology 395:615-27.

Arnold K, Owens I. 1998. Cooperative breeding in birds: a comparative test of the life history hypothesis. Proceedings of the Royal Society of London. Series B: Biological Sciences 1998 vol: 265 (1398) pp: 739-745

Avise, J.C. 2002. Genetics in the Wild. Smithsonian Institution Press, Washington, D.C. (248 pp.). [the book is now with Random House Publishers]

Barlow GW. 1988. Monogamy in relation to resources. In: The ecology of social behaviour. pp. 55-79 in: C.N. Slobodchikoff (ed.). The ecology of social behavior. San Diego: Academic Press.

Bastian M., Heymann S., Jacomy M. 2009. Gephi: An Open Source Software for Exploring and Manipulating Networks.

Bayerl H., Kraus RHS., Nowak C., Foerster DW., Fickel J., Kuehn R. 2018. Fast and cost-effective single nucleotide polymorphism (SNP) detection in the absence of a reference genome using semideep next-generation Random Amplicon Sequencing (RAMseq). Molecular Ecology Resources 18:107-117. DOI: 10.1111/1755-0998.12717. 
373 Cadwallader PL. 1977. J.O. Langtry's 1949-50 Murray River investigations. Melbourne.

374 Chapman DD., Prodöhl PA., Gelsleichter J., Manire CA., Shivji MS. 2004. Predominance of 375 genetic monogamy by females in a hammerhead shark, Sphyrna tiburo: Implications for shark 376 conservation. Molecular Ecology 13:1965-1974. DOI: 10.1111/j.1365-294X.2004.02178.x.

377 David G. Chapple. 2003. Ecology, life-history, and behavior in the australian scincid 378 genus Egernia, with comments on the evolution of complex sociality in lizards, 379 Herpetological Monographs, 17(1), 145-180

380 Macdonald SJ., Pastinen T., Genissel A., Cornforth TW., Long AD. 2005. A low-cost open-source 381

382

383

384

385

386

387

388

389

390

391

392

393

Csardi G., Nepusz T. 2006. The igraph software package for complex network research.

Cooke SJ., Suski CD. 2005. Do we need species-specific guidelines for catch-and-release recreational angling to effectively conserve diverse fishery resources? Biodiversity and Conservation 14:1195-1209. DOI: 10.1007/s10531-004-7845-0.

Couch A. 2018. Murray Cod : Distribution, Dispersal and Hybridisation in the Upper Murrumbidgee River. PhD Thesis, University of Canberra.

Couch AJ., Unmack PJ., Dyer FJ., Lintermans M. 2016. Who's your mama? Riverine hybridisation of threatened freshwater Trout Cod and Murray Cod. PeerJ 4:e2593. DOI: 10.7717/peerj.2593.

Couch A., Young M. 2016. Larval Murray Cod Genomic DNA extraction - Salting Out. DOI: 10.6084/m9.figshare.33627 figshare. 82.v1.

Courtois B., Audebert A., Dardou A., Roques S., Ghneim-Herrera T., Droc G., Frouin J., Rouan L., Goze E., Kilian A., Ahmadi N., Dingkuhn M. 2013. Genome-wide association mapping of root traits in a japonica rice panel. PLoS ONE 8. DOI: 10.1371/journal.pone.0078037.

Cruz VM V., Kilian A., Dierig DA. 2013. Development of DArT Marker Platforms and Genetic Diversity Assessment of the U.S. Collection of the New Oilseed Crop Lesquerella and Related Species. PLoS ONE 8:1-13. DOI: 10.1371/journal.pone.0064062. InterJournal Complex Sy:1695. DOI: 10.1177/001316446902900315. 
401 Desjardins JK., Fitzpatrick JL., Stiver KA., Van der Kraak GJ., Balshine S. 2008. Costs and 402 benefits of polygyny in the cichlid Neolamprologus pulcher. Animal Behaviour 75:1771403 1779. DOI: 10.1016/j.anbehav.2007.09.037.

404 DeWoody JA., Fletcher DE., Wilkins SD., Nelson WS., Avise JC. 2000. Genetic monogamy and 405 biparental care in an externally fertilizing fish, the largemouth bass (Micropterus salmoides). Proceedings of the Royal Society B: Biological Sciences. DOI: 10.1098/rspb.2000.1302.

407 408 409

410

412 413

414

415

416

417

418

419

420

421

422

423

424

425 426

427 428

Daly-Engel TS., Grubbs RD., Holland KN., Toonen RJ., Bowen BW. 2006. Assessment of multiple paternity in single litters from three species of carcharhinid sharks in Hawaii. Environmental Biology of Fishes 76:419-424. DOI: 10.1007/s10641-006-9008-5.

Donaldson TJ. 1989. Facultative monogamy in obligate coral-dwelling hawkfishes (Cirrhtidae). Environmental Biology of Fishes 26:295-302. DOI: 10.1007/BF00002466.

Donaldson ZR., Young LJ. 2008. Oxytocin, vasopressin, and the neurogenetics of sociality. Science (New York, N.Y.) 322:900-904. DOI: 10.1126/science.1158668.

ESRI. 2013. ArcGIS Desktop: Release 10.2. Redlands $C A$.

FitzSimmons NN., Moritz C., Moore SS. 1995. Conservation and dynamics of microsatellite loci over 300 million years of marine turtle evolution. Molecular biology and evolution 12:432440.

Gilligan D., Schiller C. 2003.Downstream transport of larval and juvenile fish in the Murray River. Available at https://www.dpi.nsw.gov.au/_data/assets/pdf file/0009/545634/FFRS50_Gilligan-and-Schiller-2003.pdf

Hatchwell B, Komdeur J. 2000. Ecological constraints, life history traits and the evolution of cooperative breeding. Animal Behaviour, vol. 59(6): 1079-1086

Henry GW., Lyle JM. 2003.The National Recreational and Indigenous Fishing Survey. Available at http://frdc.com.au/Archived-Reports/FRDC Projects/1999-158-DLD.pdf

Huisman J. 2017. Pedigree reconstruction from SNP data: parentage assignment, sibship clustering and beyond. Molecular Ecology Resources. 17(5): 1009-1024

Humphries P. 2005. Spawning time and early life history of Murray cod, Maccullochella peelii (Mitchell) in an Australian river. Environmental Biology of Fishes 72:393-407. 
429 Jombart T. 2008. adegenet: a R package for the multivariate analysis of genetic markers.

430 Bioinformatics (Oxford, England) 24:1403-5. DOI: 10.1093/bioinformatics/btn129.

431 Jombart T., Devillard F., Balloux S. 2010. Discriminant analysis of principal components: a new

432 method for the analysis of genetically structured populations. BMC Genetics 11. DOI:

433 doi:10.1186/1471-2156-11-94.

434 Kilian A., Wenzl P., Huttner E., Carling J., Xia L., Blois H., Caig V., Heller-Uszynska K., Jaccoud

435 D., Hopper C., Aschenbrenner-Kilian M., Evers M., Peng K., Cayla C., Hok P., Uszynski G.

436 2012. Diversity arrays technology: A generic genome profiling technology on open platforms.

437 Methods in Molecular Biology 888:67-89. DOI: 10.1007/978-1-61779-870-2-5.

438 King JR., Withler RE. 2005. Male nest site fidelity and female serial polyandry in lingcod

439 (Ophiodon elongatus, Hexagrammidae). Molecular Ecology 14:653-660. DOI:

$440 \quad 10.1111 / j .1365-294 X .2005 .02438 . x$.

441 Kleiman DG. 1981. Correlations Among Life History Characteristics of Mammalian Species

442 Exhibiting Two Extreme Forms of Monogamy. In: Alexander RD, Tinkle DW, Press C eds.

443 Natural Selection and Social Behavior. San Francisco: Chiron Press, 332-344.

444 Koehn JD., Harrington DJ. 2005. Collection and distribution of the early life stages of the Murray $445 \operatorname{cod}$ (Maccullochella peelii peelii) in a regulated river. Australian Journal of Zoology 53:137446 144. DOI: http://dx.doi.org/10.1071/ZO04086.

447 Koehn JD., Harrington DJ. 2006. Environmental conditions and timing for the spawning of Murray $448 \quad \operatorname{cod}$ (Maccullochella peelii peelii) and the endangered trout cod (M. macquariensis) in 449 southeastern Australian rivers. River Research and Applications 22:327-342. DOI:

451 Koehn JD, McKenzie JA, O’Mahony DJ, Nicol SJ, O’Connor JP, O’Connor WG. 2009.

452 Movements of Murray cod (Maccullochella peelii peelii) in a large Australian lowland river. 453 Ecology of Freshwater Fish 18: 594-602.

454 Koehn JD., Nicol SJ. 2016. Comparative movements of four large fish species in a lowland river. 455 Journal of Fish Biology 88:1350-1368. DOI: 10.1111/jfb.12884.

456 Koehn JD., O'Connor W. 1990. Biological Information for Management of Native Freshwater $457 \quad$ Fish in Victoria. Melbourne. 
458 Koehn JD., Todd CR. 2012. Balancing conservation and recreational fishery objectives for a 459 threatened fish species, the Murray cod, Maccullochella peelii. Fisheries Management and 460 Ecology 19:410-425. DOI: 10.1111/j.1365-2400.2012.00856.x.

461 Kvarnemo C., Moore GI., Jones AG., Nelson WS., Avise JC. 2000. Monogamous pair bonds and 462 463 mate switching in the Western Australian seahorse Hippocampus subelongatus. Journal of Evolutionary Biology 13:882-888. DOI: 10.1046/j.1420-9101.2000.00228.x.

Lintermans M. 2007. Fishes of the Murray-Darling Basin: An Introductory Guide. Canberra: Murray Darling Basin Authority.

466

467

468

469

470

471

472

473

474

475

476

477

478

479

480

481

482

483

484 485

Lintermans M., Phillips B. (eds.) 2005. Management of Murray Cod in the Murray-Darling Basin: Statement, Recommendations and Supporting Papers. Canberra: Murray-Darling Basin Commission Postal.

Mock DW., Fujioka M. 1990. Monogamy and long-term pair bonding in vertebrates. Trends in Ecology and Evolution 5:39-43. DOI: 10.1016/0169-5347(90)90045-F.

Morley JI., Balshine S. 2002. Faithful fish: Territory and mate defence favour monogamy in an African cichlid fish. Behavioral Ecology and Sociobiology 52:326-331. DOI: 10.1007/s00265-002-0520-0.

Nock CJ., Elphinstone MS., Rowland SJ., Baverstock PR. 2010. Phylogenetics and revised taxonomy of the Australian freshwater cod genus, Maccullochella ( Percichthyidae ). Marine and Freshwater Research 61:980-991.

NSW Department of Primary Industries. 2017.Freshwater bag and size limits. Available at https://www.dpi.nsw.gov.au/fishing/recreational/fishing-rules-and-regs/freshwater-bag-andsize-limits (accessed November 29, 2017).

Pew J., Wang J., Muir P., Frasier T. 2015. related: an R package for analyzing pairwise relatedness data based on codominant molecular markers. Molecular Ecology Resources 15:557-561.

R Development Core Team., R Core Team. 2013. R: A Language and Environment for Statistical Computing. R Foundation Statistical Computing.

Raman H., Raman R., Kilian A., Detering F., Carling J., Coombes N., Diffey S., Kadkol G., Edwards D., McCully M., Ruperao P., Parkin IAP., Batley J., Luckett DJ., Wratten N. 2014. 
Genome-wide delineation of natural variation for pod shatter resistance in Brassica napus. PLoS ONE 9. DOI: 10.1371/journal.pone.0101673.

Razick S. 2016. Cost effective research with bioinformatics. In: International Research Symposium on Pure and Applied Sciences. Colombo, Sri Lanka: Faculty of Science, University of Kelaniya, Sri Lanka.

492

Reynoldson N. 2017.2017 / 2018 Native Fish Stocking Plan for Dams and Lakes. Available at

Rourke ML., McPartlan HC., Ingram BA., Taylor AC. 2009. Polygamy and low effective population size in a captive Murray cod (Maccullochella peelii peelii) population: Genetic implications for wild restocking programs. Marine and Freshwater Research 60:873-883. DOI: 10.1071/MF08218.

Rowland SJ. 1993. Maccullochella ikei, an endangered species of freshwater cod (Pisces: Percichthyidae) from the Clarence River system, NSW and M. peelii mariensis, a new subspecies from the Mary River system, Qld. Records of the Australian Museum 45:121-145. DOI: 10.3853/j.0067-1975.45.1993.132.

Ryan T., Lennie R., Lyon J., O’Brien T. 2001. Thermal Rehabilitation of the Southern MurrayDarling Basin. Final Report to Agriculture, Forestry, Fisheries. Melbourne.

Sogabe A. 2011. Partner recognition in a perennially monogamous pipefish, Corythoichthys haematopterus. Journal of Ethology 29:191-196. DOI: 10.1007/s10164-010-0236-y.

Sogabe A., Yanagisawa Y. 2007. Sex-role reversal of a monogamous pipefish without higher potential reproductive rate in females. Proceedings of the Royal Society B 274:2959-2963. DOI: $10.1098 / \mathrm{rspb} .2007 .1041$.

Steinwender B., Koblmüller S., Sefc KM. 2012. Concordant female mate preferences in the cichlid

510 Tableau. 2013.Tableau Desktop Analytics. Available at http://www.tableausoftware.com/

511 Takahashi T., Ochi H. 2012. Invisible pair bonds detected by molecular analyses. Biology letters 512 8:355-357. DOI: 10.1098/rsbl.2011.1006.

513 Tatarenkov A., Barreto F., Winkelman DL., Avise JC. 2006. Genetic Monogamy in the Channel 
514 Catfish, Ictalurus Punctatus, a Species with Uniparental Nest Guarding. Copeia 2006:735-

515

516

517

518

519

520

521

522

523

524

525

526

527

528

529

530

531

532

533

534

535

536

537

538

539

741. DOI: 10.1643/0045-8511(2006)6[735:GMITCC]2.0.CO;2.

Turner G. 1986. Teleost Mating Systems and Strategies. In: Pitcher TJ ed. The Behaviour of Teleost Fishes. Boston, MA: Springer US, 253-274. DOI: 10.1007/978-1-4684-8261-4_10.

Vandeputte M., Haffray P. 2014. Parentage assignment with genomic markers: A major advance for understanding and exploiting genetic variation of quantitative traits in farmed aquatic animals. Frontiers in Genetics 5:1-8. DOI: 10.3389/fgene.2014.00432.

Vincent ACJ., Sadler LM. 1995. Faithful pair bonds in wild seahorses, Hippocampus whitei. Animal Behaviour 50:1557-1569. DOI: 10.1016/0003-3472(95)80011-5.

Vogel MT. 2003. The effects of varying temperature and feeding levels on somatic and otolith growth in Murray cod, Maccullochella peelii peelii (Mitchell) larvae. La Trobe University, Wodonga, Victoria, Australia.

de Waal FBM., Gavrilets S. 2013. Monogamy with a purpose. Proceedings of the National Academy of Sciences of the United States of America 110:15167-8. DOI: 10.1073/pnas.1315839110.

Whiteman EA., Côte IM. 2004. Monogamy in marine fishes. Biological reviews of the Cambridge Philosophical Society 79:351-75. DOI: 10.1017/S1464793103006304.

Wickham H. 2009. ggplot2: Elegant Graphics for Data Analysis. New York: Springer-Verlag.

Wong MYL., Munday PL., Jones GP. 2005. Habitat Patch Size, Facultative Monogamy and Sex Change in a Coral-dwelling Fish, Caracanthus unipinna. Environmental Biology of Fishes 74:141-150. DOI: 10.1007/s10641-005-6715-2.

Ye Q., Butler G., Forbes J., Giatas G., Ingram B., Koehn J., Lintermans M., Zampatti B., Beitzel M., Brooks S., Gilligan D., Hunt T., Kind P., Todd C. 2016.Murray Cod Maccullochella peelii. In Status of Australian fish stocks reports 2016. Available at http://fish.gov.au/Overview/Introduction/What-are-the-Status-of-key-Australian-fish-stocksreports-2016 
Figure 1

Upper Murrumbidgee river study area.

Collection sites are shown in bold black text and putative barriers to adult fish migration are shown in red text. Barriers from F Dyer, M Lintermans \& A Couch (2014, unpublished data). 


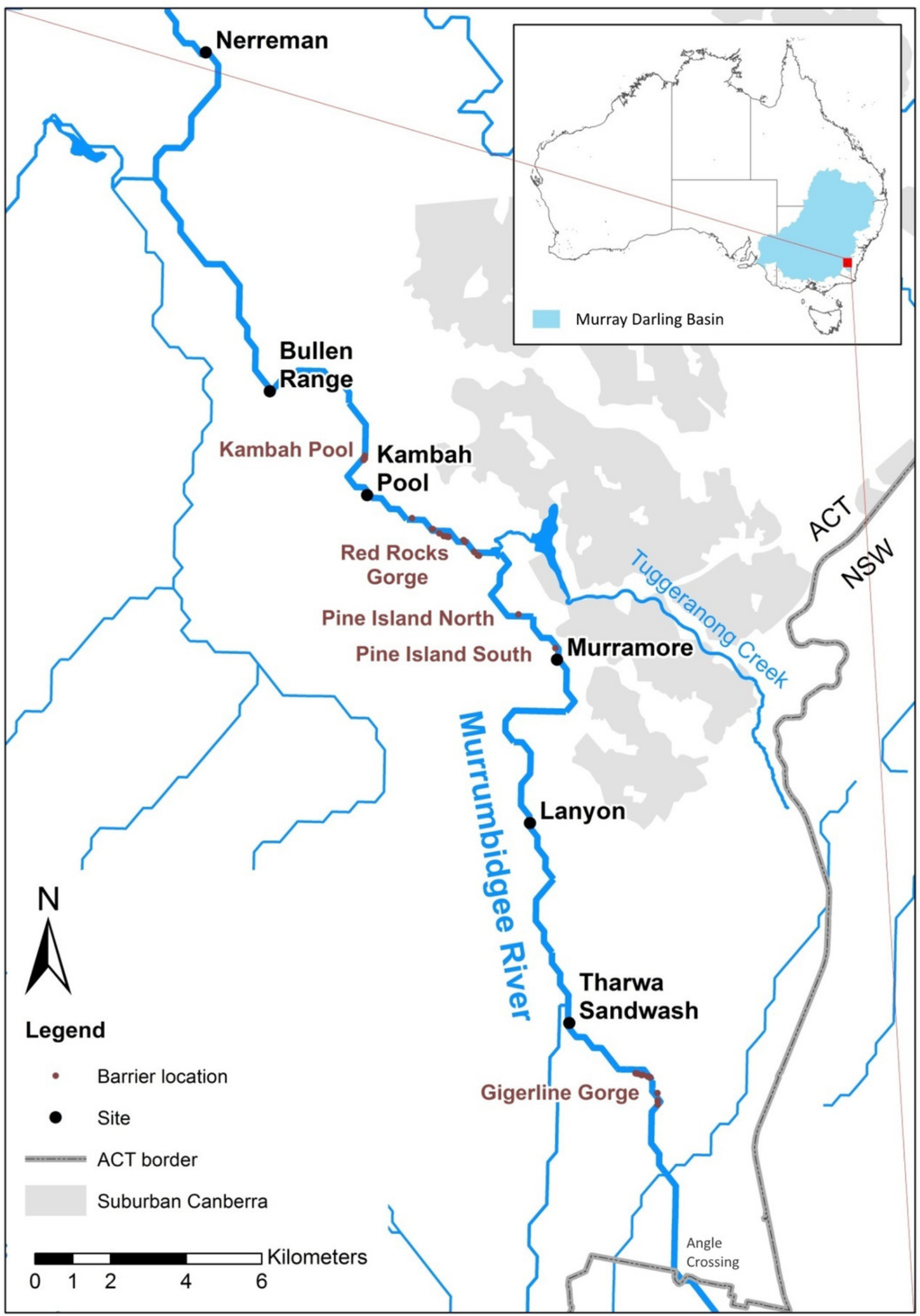


Figure 2

Inferring existence of family groups using spatio-temporal data.

Coloured by year. 2011 (blue circle), 2012 (orange square), 2013 (green cross)

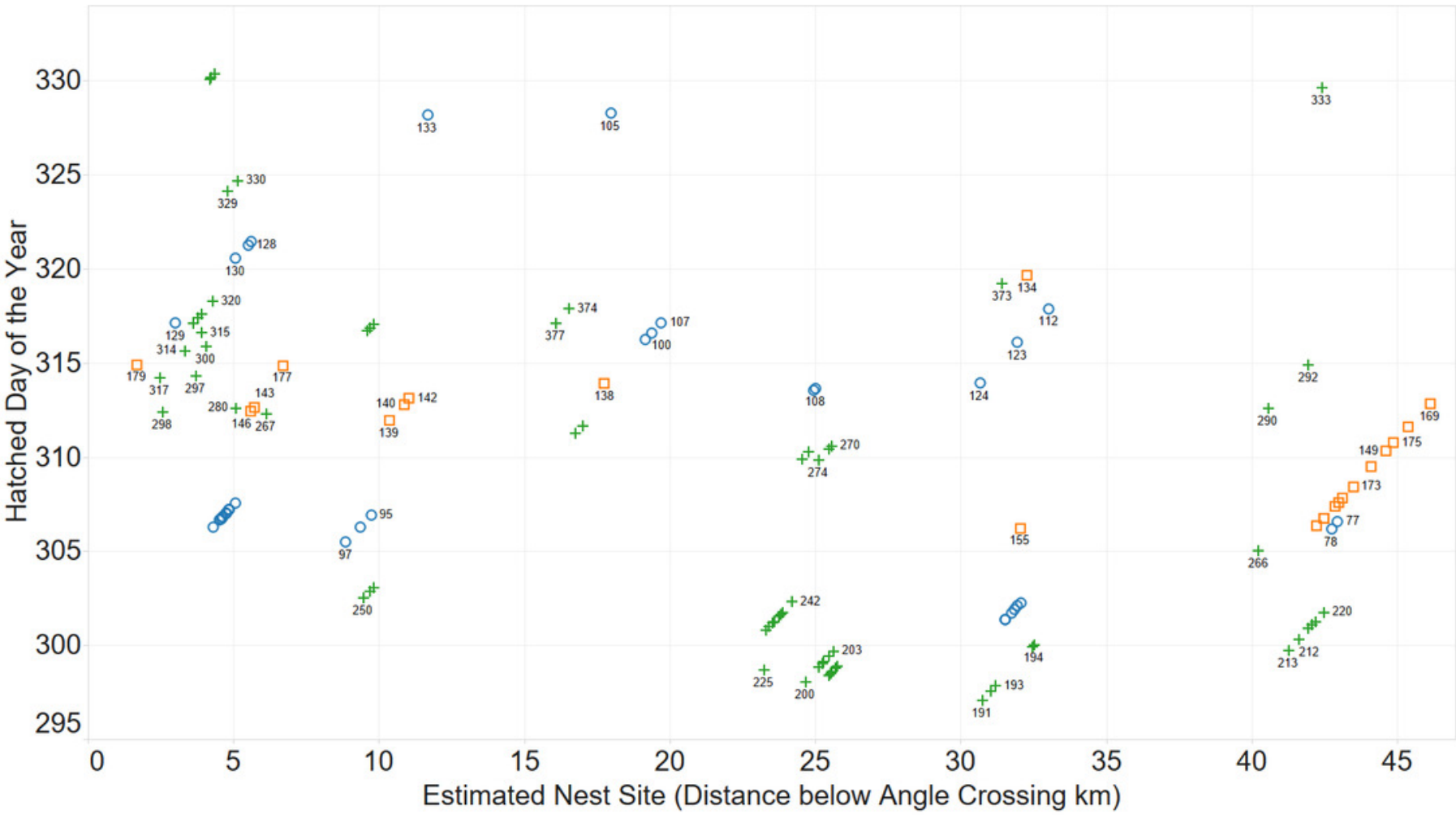




\section{Figure 3}

Full sibling dyads were identified and assigned a putative female parent name.

Full sibling larvae from multiple years are boxed. The rest are full sibling pairs found only within that one year. Singleton larvae - those without any identified full siblings - are not shown. 


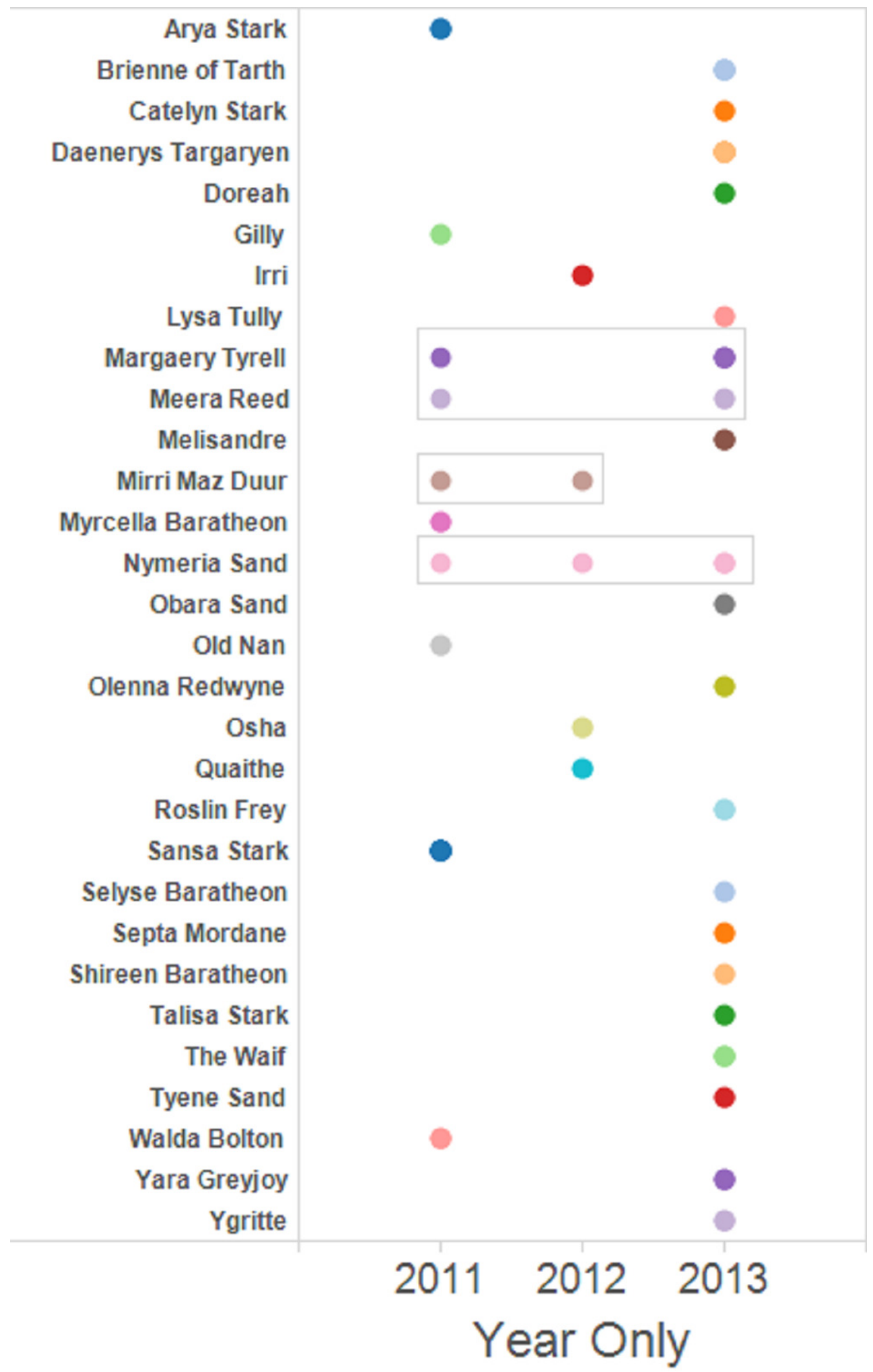


Figure 4

Inferring existence of family groups using spatio-temporal data coloured by the nominal female parent.

Some larval labels and two mother's names are shown for reference. Larval sibling pairs collected from adjacent sites are 140,179; 133,105 and 170,191.

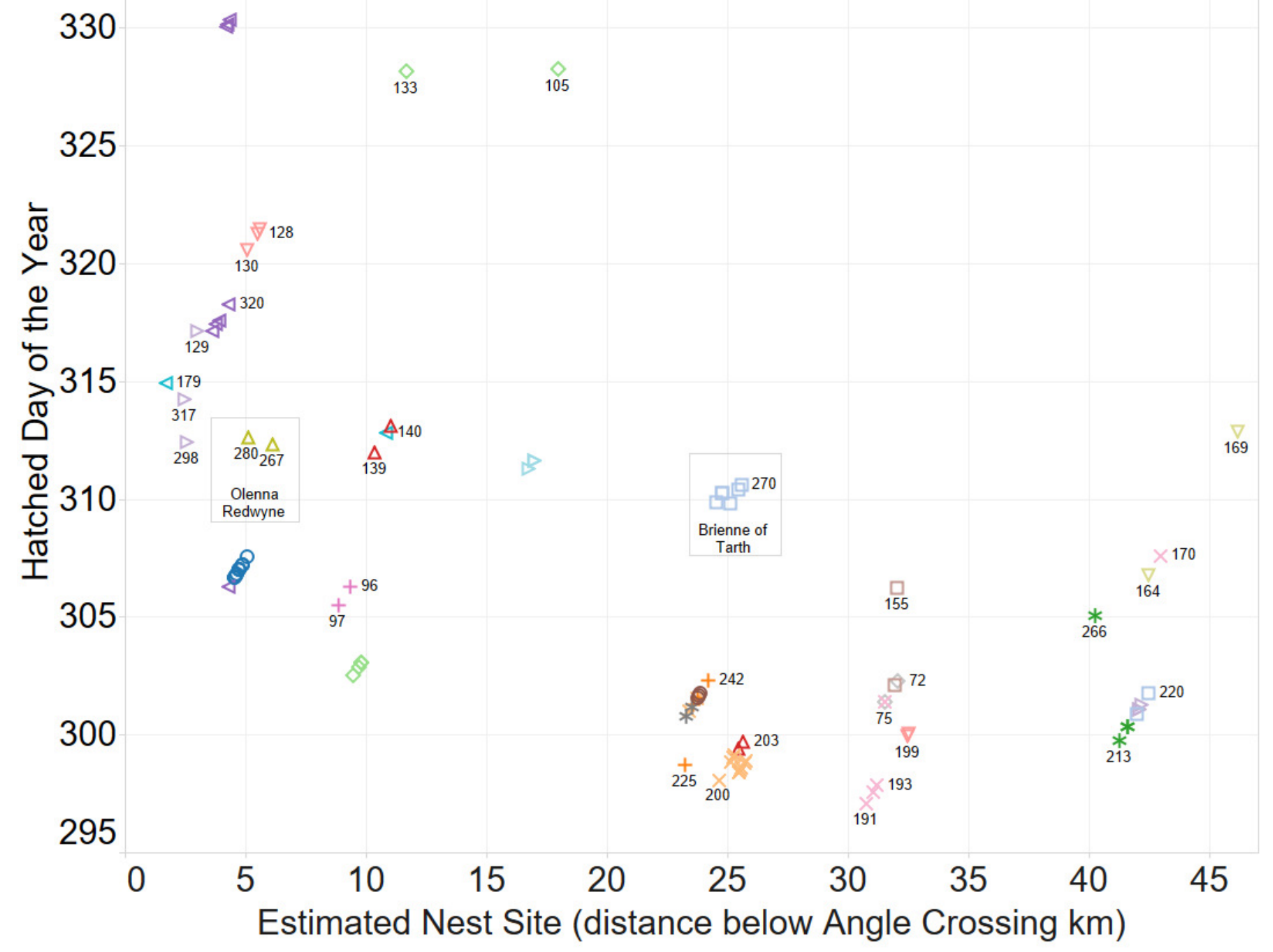


Figure 5

$815 \mathrm{~N}$ and $813 \mathrm{C}$ stable isotope ratio plot coloured by nominal female parent.

Some larval labels and two mother's names are shown for reference.

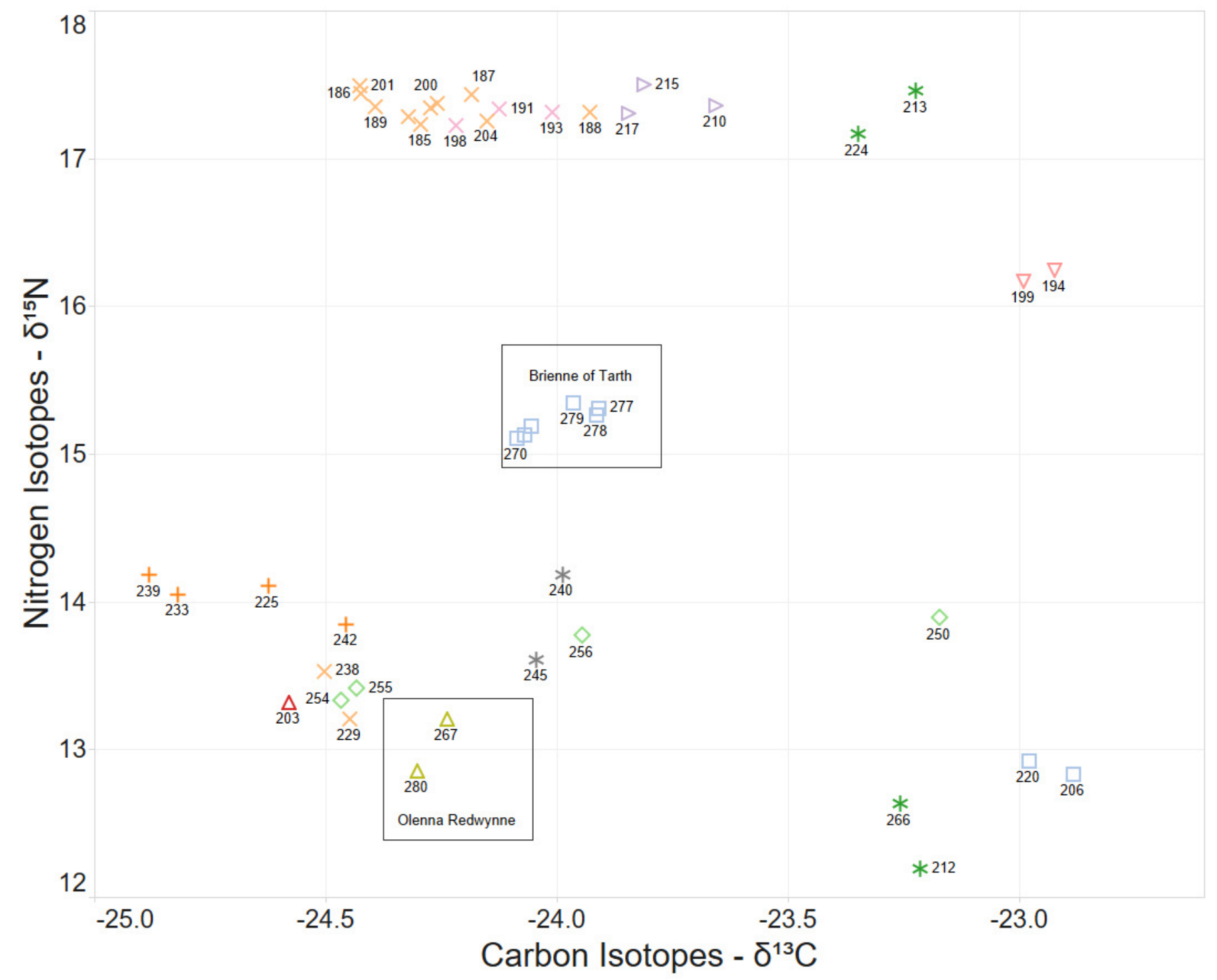


Figure 6

Probability density function for relatedness ( $r$ ) as simulated by ' $r$ package related and based on the allele frequencies in larval Murray cod 2011-2013 in the Murrumbidgee River.

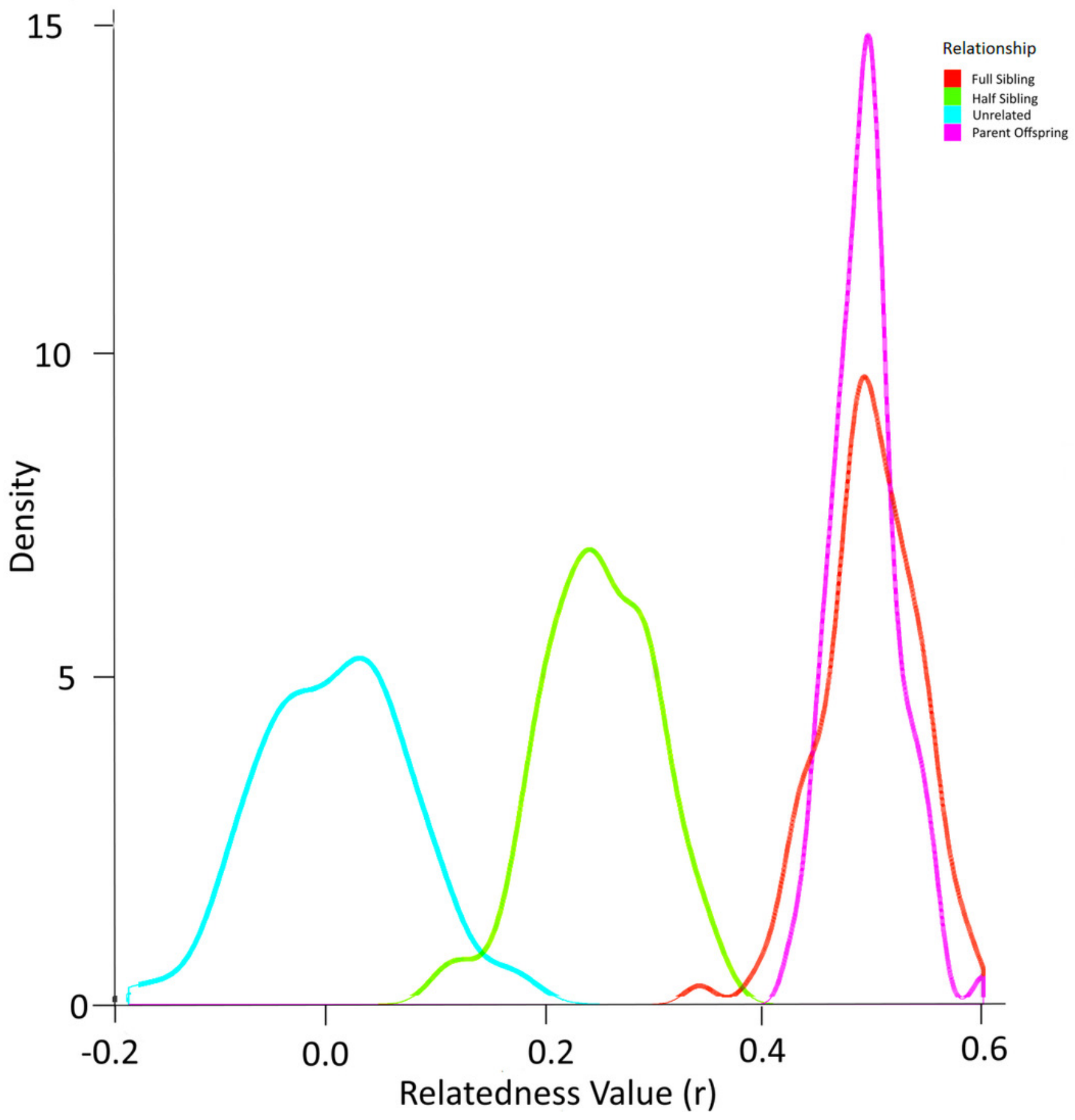

